\title{
WRITING PERSONAL ESSAYS BETWEEN THE HUNDRED FLOWERS CAMPAIGN AND THE CULTURAL REVOLUTION: FENG ZIKAI, CONFORMIST AND AUTHENTIC
}

\author{
DUŠAN ANDRŠ
}

\begin{abstract}
This study examines Feng Zikai's essays from 1956 to 1965 as products of his attempts to come to terms with the social, political, and cultural situation of the era through writing literary pieces and essays. This analysis of his prose writings that were created over a ten-year stretch bookmarked by the Hundred Flowers Campaign and the Cultural Revolution presents Feng Zikai's hesitant reassessment of his own work, its intellectual and artistic foundations, and his difficult search for a conformist but at the same time authentic essayistic voice that would allow him to grasp and accept the reality of this period.
\end{abstract}

Keywords: Feng Zikai; essay; early PRC; conformity and independent voice

Painter and essayist Feng Zikai 丰子恺 (1898-1975), one of the leading art and pedagogical figures in Republican China, settled in Shanghai in April 1949 after spending several turbulent years as a war refugee. One month later he witnessed the occupation of the city by Communist troops. This was a major turning point in his life, prefiguring the beginning of an entirely new phase in his professional career under the conditions of the new China (Barmé 2002, 278).

During the first few years after the establishment of the People's Republic of China (PRC), Feng Zikai tried adapting to the rapidly changing conditions in the country in many ways. Among other things, he began to study Russian intensively so that he could dedicate himself to a politically unproblematic activity: translating Russian and Soviet works of fiction and nonfiction. ${ }^{1}$ As a "patriotically oriented" member of the educated class of "the old society" he held a series of functions in several cultural organizations and institutions, which guaranteed him a relatively stable, state-sponsored existence (Barmé

\footnotetext{
In 1951 Feng Zikai began reading Turgenev's Sketches from a Hunter's Album and Tolstoy's War and Peace. In 1952 he published a translation of Sketches from a Hunter's Album; a second edition came out in 1955. In 1953 he translated and published a Soviet work focused on music and art education (Shi Xiaofeng 2006, 331-32). Even though in 1952, as part of his self-criticism, he committed himself to translating contemporary Soviet literature, most of the titles he translated were works of pre-revolutionary Russian literature (Barmé 2002, 307).
} 
2002, 308; Shi Xiaofeng 2006, 331-32). At the same time, however, he, like other non-party "cultural workers", was regularly subjected to pressure aimed at "correcting his mentality”. Feng Zikai was not always just a victim. In June 1955, for example, he was actively engaged in the campaign against Hu Feng, a bold critic of Mao Zedong's understanding of literature, whom he publicly denounced in an article. ${ }^{2}$

As several scholars have noted, in the second half of the 1950s and the first half of the 1960s Feng Zikai published many essays in which he uncritically and often superficially "praised the new society" (Zhuang 2020, 346). His extolments, which often came in the form of greetings for the New Year, the founding of the PRC, and International Children's Day, include the short essay “Minor Impression" (“Xiaogan” 小感) from late September 1957. In it, Feng Zikai describes his surprise at discovering that the ambulance driver who took his ill daughter to the hospital demanded an exceptionally low fee for his work. Here, he sees proof that in the short period that had elapsed since the founding of a new China, the people had already acquired "the virtues of the new society" (Feng Zikai wenji $6,469)$. Equally forced praise of the new society can also be found in his "New Year Sketch" (“Xinnian suibi” 新年随笔) from late 1960. ${ }^{4}$ A rickshaw driver that Feng Zikai has hired refuses to accept money from his customer, whom he recognizes as a famous painter. Feng Zikai is so struck by the driver's high-mindedness that he proclaims: "corrupt society has already transformed into a realm of noble people, and hell has already become paradise" (Feng Zikai wenji 6, 549). ${ }^{5}$

Feng Zikai was undoubtedly earnest in his efforts to seek out the brighter side of his situation and of the society in which he lived. At the same time, however, he also regularly experienced disillusionment, and the intellectual rigidity and the lack of creative freedom of the era weighed heavily on him. His essays were significantly marked by his efforts to come to terms with the social, political, and cultural situation of his day. Besides texts that were evidently created for reasons beyond the need for self-expression, in the second half of the 1950s and the early 1960s Feng Zikai wrote and published several essays that can be read as evidence that even in this difficult time he had not fully given up on trying to find an authentic voice as an essayist.

In his third collection of Paintings to Protect Life (Husheng ji 护生集) which was published in 1949, Feng Zikai included a manhua 漫画 ${ }^{6}$ painting titled “Cutting Evergreens Reminds Me of Something” (“Jian dongqing lianxiang” 剪冬青联想). In the lower por-

2 “Yancheng hu'e buquan de Hu Feng fangeming fenzi” 严惩怙恶不悛的胡风反革命分子. Meishu 美术7 (1955), 8-9. Worth noting is that this article heaping accusations on Hu Feng was not included in Feng Zikai's collected works, Feng Zikai wenji (1992). Barmé conjectures that Feng Zikai might have "exchanged" his ideological commitment for the ability to continue corresponding with people abroad, specifically with the Buddhist monk Guangqia living in Singapore (Barmé 2002, 309).

“Xiaogan" 小感. Wenhuibao 文汇报, 27 September 1957.

This piece was written on 29 November 1960 for Zhongguo xinwenshe 中国新闻社.

The following essays by Feng Zikai can be read as uncritical laudations of the new society: "A Lesson Superior to a Ten-year Study" (“Sheng du shinian shu” 胜读十年书; 1958), “Spring Visit to West Lake" (“Xihu chunyou” 西湖春游; 1958), “Sketching in Hangzhou” ("Hangzhou xiesheng” 杭州写 生; 1959), “A Letter to an Old Friend in Taiwan” “"Zhi Taiwan yi jiuyou shu” 致台湾一旧友书; 1960), “Happy Children" (“Xingfu ertong” 幸福儿童; 1961), “A New Happiness" (“Xin de huanxi” 新的欢 喜; 1962), “Trying My Hand at Writing during New Year's Time” (“Xinchun shibi” 新春试笔; 1963), "A Minor Matter" ("Yi jian xiaoshi” 一件小事; 1964?).

6 Feng Zikai's manhua are ink wash paintings often of a lyrical nature. Besides satirical and critical manhua possessing significant features of classical caricature, Feng Zikai also produced manhua 
tion of the image is a gardener cutting a hedge with garden shears. In the upper section, we see a giant pair of garden shears, controlled by the invisible hands of a giant, cutting off the heads and body parts of a line of figures. Thirteen years later, in 1962, Feng Zikai used the same motif in an article published in Jiefang ribao 解放日报 (Liberation Daily). ${ }^{7}$ Whereas in this manhua from the collection Paintings to Protect Life, Feng Zikai encouraged his contemporaries not to cause pain and suffering to living creatures, in his later article, which is a transcription of a speech he gave at the Second Congress of Shanghai Representatives of Cultural Workers, he addressed the devastating impact of the political turn of events that had occurred in previous years. In the relatively peaceful era following the economic collapse and chaos of the Great Leap Forward, Feng Zikai employed the metaphor of a cold-hearted gardener to criticize uniformity of thought and the lack of artistic freedom. Feng Zikai speaks about mutilated, crooked flowers and bushes that "if they could talk, and were free to speak their minds, they would certainly cry out in protest” (Feng Zikai wenji 6, 631). He covers his otherwise open criticism by referring to Mao Zedong's cultural policy and to Mao himself, ${ }^{8}$ and he demands the freedom to grow for all flowers without exception. By referencing the motto of the Hundred Flowers Campaign of 1956-57 he was simultaneously demanding equality and the freedom to grow for silent and silenced flowers, for only thus can a "true blooming of all flowers" occur (Feng Zikai wenji 6, 630).

For Feng Zikai, 1962 marked a return to a relatively peaceful personal and professional life, in the reality of a new China from a period before the turbulence stemming from the ground-breaking changes of the Hundred Flowers Campaign and the revolutionary fervour of the Great Leap Forward. Feng Zikai was re-elected chairman of the Shanghai Artists Association, he began translating the classic Japanese novel The Tale of Genji (Genji monogatari 源氏物语), his manhua were regularly published in the Hong Kong newspaper Xin wanbao 新晚报 (New Evening News), and the Shanghai Documentary Film Studio presented him as the creator of remarkable paintings in the short film The Painter Feng Zikai (Feng Zikai huajia 丰子恺画; Barmé 2002, 322, Shi Xiaofeng 2006, 334).

As indicated by his above mentioned criticism of the state of culture and the conditions under which artists and writers lived and worked between 1957 and 1961 Feng Zikai saw himself as one of the mutilated and silenced flowers in the garden of art that was cultivated by the state and the party. If we carefully read his essays from this era, we discover that despite his clearly earnest attempts to present his ideas and writings that conformed with the political ideology of the era, Feng Zikai regularly expressed an authentic, erudite, and often highly critical voice.

that were typically reflective and subjective and that sought to elicit an emotional response from the viewer.

7 “Wo zuole si shou shi. Zai Shanghai di'er ci wendai dahui shang de fayan”我作了四首诗. 在上海第 二次文代大会上的发言. Jiefang ribao 解放日报, 12 May 1962 .

8 Feng Zikai recalls the twentieth anniversary of the Yan'an Forum and calls for Mao Zedong's cultural policies to be followed (Feng Zikai wenji 6, 629). In his commentary on the last of the four poems, whose "interpretation" is the pretence for his essay, he justifies rearranging the normal order of syllables in the four-syllable phrase by stating that he was trying to create the proper tone pattern for the verse. He supports the legitimacy of his approach by pointing out that "the verse of Mao Zedong also pays attention to the alternating of tones and we should learn this from him" (Feng Zikai wenji 6, 630). 
Four months before the Hundred Flowers Campaign was launched, Feng Zikai wrote the essay “My Aspirations" ("Wo de xinyuan” 我的心愿) in response to the conclusions of a conference held in January 1956. ${ }^{9}$ The central figure at this conference, which was focused on the "question of intellectuals", Zhou Enlai, put forth the thesis that intellectuals, who in the PRC had become "a part of the working class", had to achieve the level of advanced world science. Feng Zikai's response to Zhou Enlai's speech is framed by ideological platitudes. The introduction includes an "expression of sincere support" and a call for every single intellectual to "step up and harness their forces" and "move science and culture forward by leaps and bounds" (Feng Zikai wenji 6, 419). In the conclusion of the essay, Feng Zikai optimistically announces that thanks to the "utmost efforts made by us intellectuals, we will soon enter the world stage as a nation with an advanced culture" (Feng Zikai wenji 6, 419). At the heart of this essay was essentially a list of all tasks that had been accomplished and those that had not yet been. Feng Zikai presents himself as a translator who in the six years that had transpired since "liberation" managed to translate into Chinese three books about art education and six volumes focused on music education meant for popular audiences. He stated that his two years of intensive Russian studies resulted in the completion of his translation of Turgenev's Sketches from a Hunter's Album and a translation in progress of Korolenko's The History of My Contemporary. But he adds that the value of his translations is diminished by several shortcomings. His "deep conviction" that his "translation work is still not of sufficient quantity or quality" is balanced out by his apologetically toned list of illnesses and ailments (pneumonia, rheumatism) that prevented him and were still preventing him from working more diligently and productively (Feng Zikai wenji 6, 419). ${ }^{10}$ Rather than being a serious attempt meant to contribute to raising the culture of the new China up to world-class status as quickly as possible, "My Aspirations" indirectly testifies to Feng Zikai's giving up on self-expression through original artistic creation. The author of witty manhua was a thing of the past. During the six years covered in the essay, Feng Zikai created practically not a single painting. ${ }^{11}$

In the essay "My Aspirations" we see Feng Zikai as an intellectual, a non-member of the Communist Party, who had undergone "thought reform" in the first half of the 1950s. During the Three-anti and Five-anti Campaigns of 1952-53, for the first time since the creation of the PRC, intellectuals were required to actively "remold their thinking" (Barmé 2002, 291). In an article published in the journal Wenyibao in March 1952 Feng Zikai was rebuked for his "bourgeois idealistic views of music" and was criticized alongside other Shanghai artists for a lack of enthusiasm and low productivity (Barmé 2002, 296-97). Four months later he would engage in self-criticism, ritually rejecting his former understanding of artistic creation based on “zest” (quwei 趣味). Afterwards as

\footnotetext{
“Wo de xinyuan” 我的心愿. Wenhuibao 文汇报, 8 February 1956.

Feng Zikai overcame his lung problems in 1955. At the time he allegedly promised that he would be more active in the positions that he had up until that point held only formally (Hawks 2017, 41).

11 Except for manhua on Buddhist motifs, intended for the Husheng ji series of collections, in this period Feng Zikai practically quit painting. He returned to creating art in the late 1950s, but only at the insistence of high-ranking functionaries. He created a series of paintings in support of the Great Leap Forward (Hawks 2017, 44).
} 
a supporter of the new regime he gained positions in several Shanghai cultural organizations and institutions (Barmé 2002, 298-301). ${ }^{12}$

Feng Zikai responded to the hopes awakened by the proclamation of the Hundred Flowers Campaign in May 1956 in his "A Discussion on Contention of Hundred Schools" (“Tan baijia zhengming” 谈百家争鸣) published in Jiefang ribao. ${ }^{13} \mathrm{He}$ welcomed the campaign as an attempt at "developing the culture of the nation" and emphasized its potential for bringing diversity back to art. He leaves out nearly all ideological phrases and in the introduction announces to readers that he will clarify his opinion about the campaign by making "comparisons to the field of art" (Feng Zikai wenji 6, 421). In doing so, Feng Zikai is trying to demonstrate the validity of his core thesis that the coexistence of opposing views and ideas is beneficial. To defend the idea that opposite does not mean antagonistic but complementary, he uses motifs that regularly featured in his Republican-era essays on art.

To justify the correctness of the policy put forward by the latest campaign, Feng Zikai works with the motif of "the distribution of complementary colours" (buse tiaohe 补色调和), which he also used in his carefully argued essays from the 1930s where he knowledgeably discussed the aesthetics of colours in traditional Chinese culture and in the modern Western "theory of colours". ${ }^{14}$ The only difference is that while in 1936 he demonstrated the complementarity of primary and secondary colours by referring to a red balustrade framed by the green foliage of willows, ${ }^{15}$ twenty years later he made his argument for the need for ideational and artistic diversity using the image of a "red banner placed amongst the greenery of trees" (Feng Zikai wenji 6, 421). However, it is not only motifs from the visual arts that lend the essay its unmistakable style. ${ }^{16}$ Feng Zikai welcomed the policy of "the contention of a hundred schools of thought" using his typical "three-tiered" argument. According to Feng Zikai, in the twentieth century Chinese culture went through three phases of development: from the disunity but diversity of the Republican period, to the unity but monotony of the period after the establishment of the New China and the unity and diversity of the early Hundred Flowers period (Feng Zikai wenji 6, 423). Let's overlook the fact that this vision of cultural development was just the product of wishful thinking, far removed from reality, and notice the pattern of development that Feng Zikai presents. He sees the development of culture as a series of changes, with each change marking a reassessment of the existing state of things to produce a new quality. Whereas the first two periods are interpreted as being opposing,

12 Feng Zikai engaged in self-criticism in an article published on 16 July 1952 in the periodical Dagongbao 大公报 (L'impartial). In it he admits that all his literary and artistic activities in the past were bad and harmful (Barmé 2002, 297-99; Zhuang 2020, 346).

13 “Tan baijia zhengming” 谈百家争鸣. Jiefang ribao 解放日报, 19 July 1956.

14 Feng Zikai's distinctive fusing of Far Eastern and Western painting traditions, his comparison of traditional Chinese artistic thought with the approaches of Western painting, and his interpretation of symbolism and the effects of colours on the senses are explored in Andrš 2005, 157-62.

15 "A Flood of Willow Branches above a Small Bridge with a Red Balustrade" ("Chilanqiao wai liuqiantiao" 赤栏桥外柳千条; Feng Zikai wenji 3, 331-35).

16 In keeping with traditional ideas about the unity of the whole and the parts, Feng Zikai makes an analogy between the propositions of the campaign and famous horizontal landscape paintings: the Song scroll Along the River during the Qingming Festival (Qingming shanghe tu清明上河图) and the Qing scroll Ten Thousand Li of the Yangzi River (Changjiang wanli tu长江万里图卷) (Feng Zikai wenji 6, 422). 
the third period not only surpasses the dialectical tensions of the earlier eras, but it also corrects their misguidedness. This type of three-stage argument, whose source of inspiration can be found in traditional Buddhist thought, is a strategy that Feng Zikai regularly applied in many of his prewar essays. ${ }^{17}$ It is clear that Feng Zikai, during the early days of the Hundred Flowers Campaign, putting his hopes in the coming of greater intellectual and artistic freedom, avoids ideological phrases and templates and tries to speak in his own essayistic voice.

The title of the December 1956 essay “In Lieu of Painting” (“Dai hua” 代画) ${ }^{18}$ suggests that Feng Zikai, in this period of relative liberation, had returned to his erstwhile perspective, that of a painter, capable of expressing through a few brushstrokes the essence of a scene he had turned his attention to because it says something substantial about people or society. Like many times in the past, Feng Zikai is captivated by "something remarkable that deserves to be depicted through means of paintings" (Feng Zikai wenji $6,505)$. He is disgusted to see, nearby a hall in which pictures celebrating the successes of building a socialist society are being exhibited, a ladder chained to a streetlamp. His following discussion about his unique perception of reality is sparked by the objection of his friend, who encourages him instead to dwell on truly hideous things like overflowing rubbish bins. Feng Zikai has a different view of the world. The padlock on the chain looks at him with "bulging eyes" and scares him away with its "gaping mouth" (Feng Zikai wenji 6, 506). The motif of a world endowed with feeling, typical of Feng Zikai's Republican-era essays, is used in this essay from the early days of the Hundred Flowers Campaign not to expound upon "empathy" and "disinterestedness" as the "most precious states of mind" 19 but to sigh over the fact that chains and locks "offend all people" because "all passers-by are seen as thieves" (Feng Zikai wenji 6, 506). This essay can be read as criticism of the inadequacy of the new society, which could still not make do without "chains and locks". It can also be understood as a lamentation over the immaturity of people as such. Such a reading is made possible by a passage in which Feng Zikai associates this street scene with one of his own manhua, "Neighbours" ("Linren” 邻人) from 1930. He recalls a situation in which his painting of two men standing on neighbouring balconies separated by an iron grille was understood as a depiction of the animosity between Japan and China and adds that he had to refute this interpretation because "the thing to which the picture is referring is primarily life, life as a whole" (Feng Zikai wenji 6, 507). In 1956's "In Lieu of Painting" Feng Zikai partly returned not only to the manner of expression that was typical of his prewar artistic and literary work but also to a vision of a humanity endowed with empathy and perceptiveness. As Hawks observes, the essay uses methods that are also typical of Feng Zikai's manhua. Its starting point is the contrast between "apparent" and "deeper" reality: the reality of the idealistic paintings exhibited in the gallery stands in contrast to the reality of the street scene, whose essence is accessible only to an observer equipped with a perceptive mind. The essayist also contrasts with his friend, as

17 The distinct structure of Feng Zikai's philosophical-religious essays from the 1920s and 1930s and its close similarity to the process of logical thinking in Chinese Mahayana Buddhism are presented in Andrš 2008, 396-408.

18 “Dai hua" 代画. Wenhuibao 文汇报, 10 December 1956.

19 A profound understanding of the world based on empathy (ganqing yiru 感情移入) and disinterestedness (wuguanxin 无关心), a pair of key concepts in Feng Zikai's aesthetics, is presented in An Dechang [Andrš] 2005. 
does the outer ugliness of the rubbish bin with the internal beauty of its function (2017, 42). It is paradoxical yet at the same time indicative that at the beginning of the Cultural Revolution this essay became a target of criticism and served as evidence of Feng Zikai's "reactionary nature". One of his detractors wrote that Feng Zikai had produced a "heinous essay" in which he "vilified the proletarian dictatorship", adding that the essayist had essentially "expressed the hope that [the proletarian dictatorship] would soon collapse" (Barmé 2002, 332).

Another essay from December 1956, “Honour” (“Jingli” 敬礼), presents an interesting view on people and society. ${ }^{20}$ Feng Zikai, absorbed in folding his arms, unwillingly squishes an ant crawling across his table. He hesitates, wondering whether he should crush the injured insect and put it out of its misery. He eventually follows the old saying "even a bad life is better than a good death" and decides to leave the ant to its fate (Feng Zikai wenji 6, 502). A while later he witnesses another ant approach the crippled ant and begin pulling it away to safety. A detailed description of the effort the ant puts into carrying its injured compatriot follows. The emphasis on mercy, empathy, and selflessness and his speaking about ants as "people" connects "Honour" with some of Feng Zikai's similarly oriented prewar essays. ${ }^{21}$ In contrast to his earlier approach, characterized by his emphasis on Buddhist empathy with everything living, now Feng Zikai honours a miniscule creature mainly because it possesses "friendly sentiment, selflessness, and the spirit of mutual aid". This pair of ants, which in the eyes of the person who is observing their extraordinary efforts with great empathy "grew and grew until it was as big as a mountain" (Feng Zikai wenji 6, 503-4), ${ }^{22}$ can be seen as an appeal to a member of the "new society", as well as to an individual acting in keeping with the morals of an empathic humanity.

The essays "In Lieu of Painting" and "Honour" demonstrate that Feng Zikai was able to take advantage of the relatively favourable situation in late 1956 to express his own perspective on the world in which he lived through treatises that contained some of the key features of his once distinctive essayistic style. However, compared to how productive Feng Zikai was as an author of personal essays in the prewar period, he rarely resorted to franker essayistic forms of self-expression in the second half of the 1950s.

Two short essays from January 1957 show that he had not fully given up on writing personal essays. The first is “Informal Essay Manhua" (“Suibi manhua” 随笔漫画), ${ }^{23}$ a text in which we find none of the ideological language that deformed most writings of this era. Feng Zikai highlights the difficulty of personal essay writing, as it is a creative form that, despite being described as "informal", requires not only inspiration but also the targeted collection of material and careful preparation. He makes similar statements about creative work, emphasizing the necessity to seek out seemingly banal themes that might point to something more substantial. This essay is a defence of literary and creative work worthy of that name, and at the same time it is a proclamatory resignation on such work if the necessary conditions for creating it do not exist. Feng Zikai states that

20 “Jingli”敬礼. Wenhuibao 文汇报, 26 December 1956.

21 Here, Feng Zikai creates a variation on a critical scene from his 1935 essay "Early Morning" ("Qingchen” 清晨) (Feng Zikai wenji 5, 634-39).

22 Here, Feng Zikai is referring to the motif of the figures of people growing larger the farther away they got from a rickshaw in Lu Xun's short-story "A Small Incident" ("Yi jian xiaoshi” 一件小事) from 1920.

23 “Suibi manhua” 随笔漫画 [original title “Yiyu”吃语]. Wenhuibao 文汇报, 12 December 1957. 
"the reason [I] have been writing much less than [I] translate recently is that [I] lack the mental strength, avoid the serious, and deal with the trivial" (Feng Zikai wenji 6, 562). With equal frankness he speaks about the obstacles that discourage him from creating manhua. He highlights the effect of manhua, which is based on focusing on one thing and which surpasses verbose, affected argumentation, and laments the difficulty of searching for a meaningful object in a world that is poor in such things. Feng Zikai also considers the act of creation in his essay "Roasted-stirred Popped Rice" (“Baochao mihua” 爆炒米 花), ${ }^{24}$ which was inspired by an encounter with a strange food offered to him by a street vendor. He lingers over "the linguistically ugly and most likely also incorrect" name given to roasted puffed rice (Feng Zikai wenji 6, 428) and mentions that the domestic worker in his house had come up with the idea of cooking stale New Year's cakes in the same way. This type of preparation renders the cakes not only soft and easier to chew, but it also makes them bigger. This culinary trick, discovered by coincidence, reminded Feng Zikai that more than thirty years previous he had done something similar with literature. In the eyes of people a generation older than he, his essays were akin to roasted New Year's cakes. Everything that he expressed through the puffed-up, inconsistently textured cakes of his "wordy essays in the spoken language" was possible to say with small, hard cakes in pentasyllabic or heptasyllabic quatrains in the classic language (Feng Zikai wenji 6, 430). In "Roasted-stirred Popped Rice" Feng Zikai speaks to us in the voice of his prewar essays. His thoughts on the distinctive expressive capabilities of the classic language and traditional poetic forms are presented in a personal essay free from ideological ballast and cliché.

Feng Zikai's exceptional perceptiveness and sensibility comprise one aspect of his artistic persona, which found expression in his personal essays from the prewar period. Therefore, one of the major themes in Feng Zikai's essays is seeking delight in scenes of daily life. Feng Zikai, however, did not avoid "more festive" delights, especially spring or autumn trips. Going for a boat ride in near or far-away locations or visiting new places a pastime that Feng Zikai shared with Ming- and Qing-era literati, writers of works in the genre of xiaopin 小品, a type of personal prose (Shi Xiaofeng 2006, 263) - were often sources of inspiration for his literary and artistic works.

The 1950s and 1960s were not conducive to individual tourism; of the few trips that Feng Zikai took in this period, several of them were essentially "voluntarily mandatory" visits to places connected with the history of the revolutionary movement. One such trip, taken in early October 1961, was an excursion to a Chinese Communist base in the Jianggang mountains in Jiangxi province. The essays in which he writes about this and other trips contain passages that could be considered, to use Barmés words, "revolutionary propaganda" $(2002,320)$. At the same time though they are also remarkable for their distinctive essayistic style, an important part of which is a focus on the joy of travelling and the delight of being in interesting places.

The first of three essays inspired by a trip to Jiujiang and Lushan, which Feng Zikai took with several family members in October 1956, is a reflection on his experiences from a steamboat cruise along the Yangzi River. "Travel Notes from Lushan, No. 1" ("Lushan

This essay was not published when Feng Zikai was alive. 
youji zhi yi” 庐山游记之一 $)^{25}$ opens with the motif of "pride in the working people", who during the war managed to repair a sunken ship, the one Feng Zikai was travelling on (Feng Zikai wenji 6: 574). He then explores patriotism by describing the feeling elicited by a song glorifying the river upon which the boat was sailing. Whereas the song that Feng Zikai sings accompanied by an accordion player awakens within him patriotic rapture and at the same time memories of his school days, the loud music and announcements that incessantly pour out of the ship's speakers are hard to bear and at best a disturbing racket. His lamentations over the unbearable noise that "overpowers everything" and that "forces everyone to listen" serve as a counterpoint to the passage immediately preceding this one in which he describes the joy he feels from singing. Feng Zikai readies himself to go and complain, but in the end "he does nothing, fearing that most people like this nonsense" (Feng Zikai wenji 6, 575). His criticism of the "excessive abundance" generated by the speakers can be understood as criticism of the pressure that people, not just those travelling on the boat, are permanently under due to indoctrination efforts. Feng Zikai tries to ignore the flood of instructions and messages, reflecting on the history of the places where they stop and observing scenes from the lives of the local inhabitants. $\mathrm{He}$ ends his essay with a reference to the subjective perception of time: "a cruise lasting three days and two nights beats a year of normal life" when it comes to experiencing a variety of sensations and getting to know new places and people (Feng Zikai wenji 6, 576).

“Travel Notes from Lushan, No. 2" ("Lushan youji zhi er" 庐山游记之二) ${ }^{26}$ in which Feng Zikai describes his impressions from a stop in Jiujiang, combines a view of the world seen through the matrix of classic poetry, the motif of a utopian society, and praise for the talents of the artisans at the local porcelain workshops. Typical of his style, Feng Zikai closes the essay with an eminently creative rendering of a random scene from daily life. To the traveller, Jiujiang, which Tang poets such as Cui Hao and Bai Juyi "had beautified through poetry", seemed to be a world of orderliness, peacefulness, and hospitality (Feng Zikai wenji 6, 577). The phrases that Feng Zikai uses to laud the virtues of local inhabitants, especially women, give the impression that the traveller had not disembarked at a river port in Jiangxi province, but in a fantasyland dreamt up in one of his Utopias. ${ }^{27} \mathrm{In}$ Feng Zikai's eyes, the employees of the local porcelain workshops were gifted with exceptional abilities; the essayist exalts the untrained nature of the folk artist whose work is not the imitation of the old models but who takes inspiration from reality. In contrast to the exceptionality that is a common feature of the sequence of impressions from Jiujiangu, in the essay's conclusion Feng Zikai focuses on a common scene, whose exceptionality lies in its artistic value. Feng Zikai's eye is caught by women washing laundry in a lake. The undulating surface creates concentrated rings around the laundresses, and thus the back of each of the women is framed by "a semicircle of small waves, reminiscent of half of a phonograph record". Feng Zikai relaxes on a mat, drinking tea, his enthusiasm about

\footnotetext{
“Lushan youji zhi yi”庐山游记之一. Wenhuibao 文汇报, 1 October 1956.

“Lushan youji zhi er" 庐山游记之二. Wenhuibao 文汇报, 3 October 1956.

An ideal society following a moral code is a motif that Feng Zikai regularly worked with in his essays; see, e.g., “An Incident from One Evening in Tokyo" ("Dongjing mouwan de shi” 东京某晚的事; 1927), or in his tales for young people, such as “The Land of the Greats" ("Daren guo" 大人国; 1936) and “The Land of Pure Hearts" ("Chixin guo" 赤心国; 1936). Feng Zikai's desire for a new, more harmonious society is discussed in Barmé 2002, 281.
} 
the new person of the new society gone, replaced by aesthetic pleasure from a "scene truly worthy of being captured in painting" (Feng Zikai wenji 60, 580).

More than just aesthetic pleasure is thematized in the last of his trio of "Lushan" essays, “Travel Notes from Lushan, No. 3" (“Lushan youji zhi san” 庐山游记之三). ${ }^{28}$ Images from classical poetry are a substantial source of Feng Zikai's imaginative perception of the mountains. The essay opens with the verse of Tang poet Qian Qi 钱起, whose image of "a monk from the Six Dynasties period" glimpsed in the foggy mountains serves Feng Zikai as the central motif of the entire essay. Considerable space is given to describing repeated encounters with a visitor to Lushan who is constantly holding a palm fan in his hand. Thanks to this "attribute", the man becomes, in the eyes of Feng Zikai, the personification of the Song monk Ji Gong 济公. Feng Zikai, who from the beginning viewed the mountains as "a heavenly space of the spring of peach blossoms", is increasingly convinced that he had met a "hidden wiseman". This random acquaintance becomes an important topic of discussion, and Feng Zikai recognizes his hidden poetic essence - the man's distinctive description of an unexpected encounter with a weasel is not unlike the verse of Yang Wanli 杨万里, master of Tang poetry (Feng Zikai wenji 6, 583-84). In the concluding passage Feng Zikai "returns to earth", or, to put it more specifically, he begins criticizing the inadequate capacity of the dining facilities. His displeasure at the fact that the workers, who once in a long while treat themselves to a moment of rest, do not have the opportunity to eat a meal and thus hike in the mountains on empty stomachs contrasts with the "heavenly" atmosphere of the preceding section. The source of "earthly" pleasure that gives the essay a humorous punchline is Tsingtao beer with its good foamy head, which the author praises at the very end of the essay (Feng Zikai wenji 6, 585).

These three essays describing a visit to Lushan present Feng Zikai as a "cultural worker", who has no doubt that after a good job done he deserves distraction and rest in the form of a several-day-long trip. ${ }^{29}$ As he approaches his destination, the Feng Zikai finding "sublime" delight in an aesthetic view of the world, who however does not overlook the "lower" pleasures of eating and drinking, gains the upper hand over the Feng Zikai experiencing feelings of pride in the successes of the new society and enchantment with the new person.

Feng Zikai took another trip in 1958, two years after his journey to Lushan. "Dream of Yangzhou" ("Yangzhou meng" 扬州梦) ${ }^{30}$ is an essayistic portrayal of a visit to Yangzhou that he undertook on 1 May with his grandson. An important part of the narrative is the motif of dreaming, more specifically, two different dreamlike visions of Yangzhou, a city about whose past Feng Zikai knows much but which he is visiting for the first time in his life. Feng Zikai drew inspiration for the trip from classic poetry praising Yangzhou, which he recites to his sick grandson. Feng Zikai presents an image of the city pieced together from the verses of famous poets and prose writers, and the essayist confronts this literary Yangzhou with the real Yangzhou. Arriving in the city aroused many conflicting feelings in Feng Zikai. Against his expectations, Yangzhou turns out to be a thor-

28 “Lushan youji zhi san”庐山游记之三. Wenhuibao 文汇报, 4 October 1956.

29 As Feng Zikai states in the introduction to the first discussed essay, he went on this trip with his family after he had "finished a translation of the first volume of Korolenko's The History of My Contemporary, which contained 300,000 characters" (Feng Zikai wenji 6, 573).

30 “Yangzhou meng”扬州梦. Xinguancha新观察, 1 May 1958. 
oughly modern city. Feng Zikai reveals his disenchantment by regularly pointing out the absence of anything old: the hotel is new, the hotel room is new, the hotel furniture is new, even the bed sheets are new (Feng Zikai wenji 6, 510). It takes a long while before Feng Zikai is capable of understanding that the city he finds himself in is ancient Yangzhou. Much of his first day spent in Yangzhou is marked by disenchantment. He is even disappointed with the meat-based meals offered in a local restaurant, which Feng Zikai, a vegetarian, "can enjoy only with his eyes" (Feng Zikai wenji 6, 510). Feng Zikai attempts to satisfy his desire to encounter Yangzhou's past by visiting the celebrated Twenty-four Bridge (Ershisi qiao 二十四桥). He provides a description of his visit that is relatively succinct, yet, typical of Feng Zikai, poignant. On the way to the bridge, the sightseers are made fun of by rickshaw drivers who do not understand why anyone would want to visit such a boring place. His brief encounter with this uninteresting monument is closed with a pointed scene: Feng Zikai's grandson recites a line of verse - "the choppy water reflected the speechless moon" - while stepping over the trickle of water that remained here after what was once a lake dried up (Feng Zikai wenji 6, 511). On the way back to the hotel, Feng Zikai recalls the verses of Tang poets while "dreaming of the blossoming Yangzhou of the Tang era" (Feng Zikai wenji 6, 512). As he realizes in the evening in his hotel room, an encounter between a person "filled with nostalgia for past times" and modern Yangzhou will necessarily end in disappointment. Feng Zikai falls asleep, and in a dream he is visited by a woman named Yangzhou, who explains to him that "over the course of more than 1,000 years she had been raped, tortured, and deformed, [her] entire body dotted with wounds" (Feng Zikai wenji 6, 513) and that "she had paid with her own blood" for the beauty of the images from the old poems. She ends her lamentation with the following words: "only in 1949 did the people free me from my chains, they treated my wounds, and cured my ailments; they bathed and fed me." Before leaving, she apologizes, saying "Forgive me for pulling you out of your beautiful dream" before parting with the words "We will see each other tomorrow!" While seeing off his visitor Feng Zikai trips and wakes up. Thanks to this unexpected visit, he "suddenly sees the light", understanding that such a "dream of Yangzhou" surpasses "the dreams of Yangzhou" of ancient poets (Feng Zikai wenji 6, 514).

"Dream of Yangzhou" is one of the essays in which Feng Zikai praises the new society and can be read as a proclamation of support for the aspirations of the new China (Zhuang 2020, 346). This essay can also be seen as a way for Feng Zikai to mock or even criticize his own weakness for ancient culture (Feng Yiyin 1983, 159). The very end of the essay, however, provides space for another interpretation: although Feng Zikai emphasizes that this "much more interesting 'dream of Yangzhou' cannot fail to be noticed" (Feng Zikai wenji 6, 514), his record of a visit from a woman named Yangzhou is only a mere appendix to the detailed description of the literary portrayal of Yangzhou and his own disillusionment with his encounter with the real Yangzhou, which are at the heart of this essay. The city gradually "grows on him" though, and in the evening he even finds a restaurant serving vegetarian meals (Feng Zikai wenji 6, 513). In the conclusion he speaks about himself as being "awakened" but says nothing at all about whether during the second day of his stay he truly saw Yangzhou through new eyes. It is worth noting that Feng Zikai has his ambivalent dream about Yangzhou during the Great Leap Forward, a campaign that resulted in, among other things, the substantial 
transformation of many cities, often at the cost of the irreversible loss of their aesthetic qualities (Spence 1990, 581).

In May 1961, during a time of gradual liberation and retreat from the policies of the Great Leap Forward, Feng Zikai took a several-day trip to the Yellow Mountains. In a trio of essays inspired by his visit of a picturesque rocks area the Feng Zikai that we know from his prewar essays speaks to us. The essay "Pines of Huangshan Mountains" (“Huangshan song” 黄山松) ${ }^{31}$ is reminiscent of his writings on trees from the 1930s in which Feng Zikai declared the need for "an artistic perspective" and which offer inspirative ponderings about the possibilities and limits to perceiving and depicting reality. ${ }^{32}$ In the period in which a new China was being built, the variously shaped pine trees growing on inhospitable cliffs strike Feng Zikai primarily due to their ability to make do with a minimum of nutrients and the strange shapes of their crowns. The branches of the Huangshan pines do not point up like those of most trees, but they grow to the side. The flat crowns of the trees are also remarkable because their branches interweave and support each other (Feng Zikai wenji 6, 587-88). The essay is interesting for the way Feng Zikai adapts his view to the new conditions and at the same time for the extent to which he tries to maintain his erstwhile essentially artistic perception.

Offering up ideological platitudes, he mentions why the willow, as one of only a few trees, has branches that hang down. In contrast to his perspective from the mid-1930s, when Feng Zikai praised the drooping branches of the willow as an expression of the humility of being, for "not a single one of them forgets about its roots" (Feng Zikai wenji 5, 388), at the beginning of the 1960s, "willow branches [are] so flexible and weak that they hang down to the ground under the pull of gravity and not because they had decided to do so themselves" (Feng Zikai wenji 6, 587). His once deep empathy, his putting himself in the place of an object come to life, was replaced with a scientific outlook. Feng Zikai, however, can still look at the world with the eyes of an artist, as his work with artistic abstractions reveals: the peculiar appearance of the crowns of the pine trees is aptly compared to a comb with broken teeth or to the character $习$. He ends the first of his three essays on his visit to the Yellow Mountains on a light note. Although he mentions that a tree whose crown is made up of a tangle of vigorous branches is called the "unity pine tree" (tuanjie song 团结松), he does not take advantage of the ideological potential of this motif. He views the tree with the eyes of a weary, enchanted pilgrim. The flat crown takes on the form of a "cushion" upon which he might be able to rest after a demanding climb (Feng Zikai wenji 6, 588-89).

In the essay “Climbing Mt. Tiandu” (“Shang Tiandu” 上天都) ${ }^{33}$ Feng Zikai presents himself as a proficient hiker who refuses, as an older person, to be carried to the top of the highest peak of the Yellow Mountains on a sedan chair. He uses the long ascent, broken up by several stops, to discuss the possibilities and limits of depicting reality through painting and photography. As a painter he prefers paintings, which, unlike photographs, can "eliminate the chaotic details" of the reality being viewed and "emphasize the essential"

31 “Huangshan song” 黄山松. Wenhuibao 文汇报, 25 May 1961.

32 "Model" essays of this type include "Willow" ("Yangliu" 杨柳, 1935) and "Chinese Parasol Tree" (“Wutongshu” 梧桐树, 1935). Feng Zikai's aesthetic perspective is presented in Andrš 2005.

33 The essay "Shang Tiandu" 上天都 was published in the Peking magazine Jiangshan duojiao 江山多 娇 in 1961. 
(Feng Zikai wenji 6, 597). A comical tone is added to the essay through the inventive interweaving of his own performance as a hiker with two "joyful" current events; the news that Chinese table tennis players had won a medal at the world championships and that Yuri Gagarin had flown to space gave him the energy needed to continue his demanding hike. The point of the entire essay comes in the concluding pentasyllablic twenty-line verse, reinforcing the parallel built up in the essay between the flight of the first man in space and the writer's ascent of Mt. Tiandu.

In "Huangshan Impressions" ("Huangshan yinxiang" 黄山印象), ${ }^{34}$ the third essay inspired by his more than ten days spent in the Yellow Mountains, Feng Zikai considers the subjectivity of perceiving natural scenery while also reflecting on encounters between the old and the new. A discussion about how different points of view transform the appearance of mountain peaks and cliffs leads him to considering how aptly named concrete landscape elements are. Feng Zikai declares himself to be a proponent of names that result out of a creative process, and therefore approves, when one visitor, contrary to more poetic naming traditions, dubs one rock tower "Hotel International", and calls it a desirable example of "contemporary aesthetic sentiment". Besides his emphasis on the subjective nature of aesthetic perception and his defence of creativity, we find another motif typical of his work in the essay: although Feng Zikai is in the heart of a picturesque landscape, he remains above all a seeker of the remarkable in the ordinary. What he brings away from his visit to the Yellow Mountains is the knowledge that everything bizarre, strange, or unordinary will gradually become ordinary, and unlike other visitors, he appreciates the "ordinary" view of the mountains from the valley (Feng Zikai wenji 6, 591).

In October 1961 Feng Zikai went on a tour of sights associated with the Chinese revolutionary movement, Communist bases in Jiangxi province, and depicted his impressions in three essays, as he did with his visits to Lushan and the Yellow Mountains. The leitmotif of these works seems to be gratitude for the revolutionaries that Feng Zikai feels during his visits to places associated with Mao Zedong and the Long March. Confronted with the primitive conditions in which Chinese Communists lived and fought in the first half of the 1930s, he feels guilty for the comfortable life he lives. In the essay "While Drinking Water, Don't Forget the Source" (“Yinshui siyuan” 饮水思源) ${ }^{35}$ he highlights the contrast between the spartan past and the prosperous present and mentions, in what comes off somewhat jokingly, the "great revolutionary lesson" he learned at the museum dedicated to the revolution in Ruijin: after having viewed the specimens of grass on display, the only source of food for the starving revolutionaries, he recognizes his own pettiness at his exasperation of having eaten lunch two hours late due to a delay during a tour of a mine (Feng Zikai wenji 6, 602). Likewise in the essay "The Fallen Petals Turned to Spring Mud, but I Cherish Them More than Before" ("Huazuo chunni geng huhua” 化作春泥更护 花 $)^{36}$ he speaks about the strong impression made on him by the hard beds the revolutionaries slept on, whereas he sleeps in a hotel on a "spring mattress" (Feng Zikai wenji 6, 604). In the third essay, titled "We Will Finish What We Have Started" "Youtou youwei"

It seems this essay was not published after it was written.

“Yinshui siyuan” 饮水思源. Jiefang ribao 解放日报, 14 October 1961.

“Huazuo chunni geng huhua” 化作春泥更护花. Wenhuibao 文汇报, 13 October 1961. 
有头有尾), ${ }^{37}$ he glimpses evidence of the "revolutionary spirit" of local inhabitants in the fact that, despite natural catastrophes, "everywhere things are being built at great speed" (Feng Zikai wenji 6, 608).

This trio of essays is remarkable for the form in which Feng Zikai expresses his gratitude to past revolutionaries and his admiration for current ones. He achieves an interesting effect by placing verses from ancient poets and his own "casual" poems nearby ideological phrases. In the first of these three essays he communicates a single message in two ways: Feng Zikai praises the revolution and revolutionaries using lofty phrases, but in the conclusion this praise comes in the form of regular pentasyllabic eight-line verse. "We Will Finish What We Have Started" includes many verses in classical forms. This essay also provides interesting evidence about how poetry was used the time in social interactions. As the "delegation" of which Feng Zikai was a part is welcomed, one of the hosts greeted his guests by reciting septasyllabic eight-line verse. In response, Feng Zikai composed on the spot a poem in the same form. Upon request, it was then recited by one of the present functionaries. The final passage of the essay is also interesting. The day before departing the city of Ganzhou, Feng Zikai gets the opportunity to visit a place that was not connected to the history of the revolution, Mount Tongtianyan, whose peak is decorated with sculptures of Buddhist deities carved into the rock. On one rock, he comes across a poem by Wang Yangming 王阳明evoking deep repose in a beautiful place. Feng Zikai wastes no time and composes his own verses, which emulate the form of the poem by this Ming-era Neo-Confucian philosopher. When he left the city the following day, he noted that "the people of Ganzhou not only possess a wealth of revolutionary spirit, but they are also rich in their sense of art" (Feng Zikai wenji 6,610 ). To say good-bye to Ganzhou, he then composes a poem in the ci form, in which, like in his previous poem, he praises the beauty of the city that he was leaving with a heavy heart. Feng Zikai also styles himself an intellectual leaning towards artistic perception in the last of three essays mapping his tour of revolutionary Jiangxi. At the end of the essay, he expresses praise for the revolutionary traditions of Nanchang in the form of a ci poem that follows the musical pattern of the tune "I Recall Jiangnan" (Feng Zikai wenji 6, 606).

Feng Zikai had several periods during his artistic career in which he strongly felt that poetry provided true, timeless testimony about the nature of people. When he was in Jiangxi, nearly twenty years had passed since he compiled his collection of verses in paintings. ${ }^{38}$ Feng Zikai lived in a thoroughly transformed world, but as the essays discussed here illustrate, poetry remained for him an irreplaceable means of relating to the world.

In February 1963 Feng Zikai travelled for several days, visiting Buddhist sights in the city of Ningbo and on Putuoshan island. He used his visit to Tiantong monastery in Ningbo to tell two stories from the life of the Japanese Zen Buddhist monk and painter Sesshū. Whereas in the essay "Remembering Sesshū While in Tiantong Monastery" (“Tiantongsi yi Xuezhou” 天童寺忆雪舟) ${ }^{39}$ Feng Zikai comes off mainly as an expert on

37 “Youtou youwei” 有头有尾. Renmin wenxue 人民文学, December 1961.

38 The collection Poetry in Paintings (Huazhong you shi 画中有诗) was published in 1943 (Barmé 2002, 124).

39 “Tiantongsi yi Xuezhou”天童寺忆雪舟. Xin wanbao 新晚报, 24 April 1963. 
traditional ink wash painting, ${ }^{40}$ the essay "The Monastery of Bodhisattva Guanyin Who Was Reluctant to Leave" (“Bu ken qu Guanyin yuan” 不肯去观音院) 41 is in the form of the notes of a pilgrim who is trying to "reconcile" the perspective of a Buddhist with that of a citizen of the new China. Feng Zikai visits this site on the feast of the boddhisattva Guanyin. He notices that the monastery that he last visited fifty years ago was recently renovated. He then describes in detail the location and appearance of each part of the monastery and recounts legends associated with its establishment: the monastery was founded by a Japanese monk whose boat, which was transporting a statue of the bodhisattva Guanyin to Japan, was blown off course to this part of the Zhoushan archipelago. Feng Zikai notes that this is evidence of "age-old relations between the people of China and Japan" and "the close relationships" between the two nations. In the conclusion, Feng Zikai describes a trip to a sandy beach near the monastery. The passage relates a peaceful walk, but the scene can also be understood as a distinctive portrayal of a Buddhist's insight into the nature of being:

Every step in the sand was so soft. It was even more pleasant than walking through a blooming meadow. I walked a bit, then I looked around. My own footprints had joined together to form long lines intersecting the sandy plain. That was reminiscent of a smooth, uninterrupted mirror. I almost felt sorry for it. On the beach lay shells of different shapes and sizes; the people walking on the sand collected them. I also picked one up and put in it my pocket so I could take it as a souvenir. I trample the beach's sand for a single shell. You're not supposed to do that! The following day, when I went to the same place, I saw a sandy beach reminiscent of a smooth, uninterrupted mirror. There wasn't a single scratch on it. (Feng Zikai wenji 6, 625)

The poem that ends the essay is reminiscent of a lyrical vision of a world of joy and peace drawn up from highly incoherent material. Feng Zikai rejoices that the monastery is as good as new, and he compares the "roaring waves driven by the Eastern wind" to the "victory cry of the Long March". He also sees how the "monastery hall is shrouded by a cloud of smoke rising from the incense burners" as "the bodhisattva Guanyin nods her head, the Buddha Maitreya smiles, and both look on with joy at the flocks of creatures rejoicing in peace and tranquillity" (Feng Zikai wenji 6, 625-26).

During the Republican era, a time of competing cultures and ideologies, Feng Zikai stood out with his conciliatory, peaceful mindset, striving for the unforced integration of the traditional and the modern, the foreign and the domestic (Shi Xiaofeng 2006: 267). The essayistic reflection on the pilgrimage to the Putuoshan Island in 1963 is a proof that Feng Zikai harboured a desire for the harmonious coexistence of different ideas and visions even in the fundamentally changed conditions of the new China.

The above-presented essays are records of mostly longer journeys that Feng Zikai went on during the second half of the 1950s and the first half of the 1960s. ${ }^{42}$ The relatively good

40 For an exhibition of Sesshū's paintings held in Shanghai Feng Zikai wrote an article titled "Sesshū and His Art" (“Xuezhou he tade yishu”雪舟和他的艺术), a well-informed piece presenting the painter as well as Japanese and Chinse ink wash painting in greater context (Feng Zikai wenji 6, 570-72).

41 “Bu ken qu Guanyin yuan” 不肯去观音院. Xin wanbao 新晚报, 18 April 1963.

42 Apart from the already discussed journeys, in this decade Feng Zikai also took shorter trips to the following locations: Moganshan (1955), Jinhua (1962), Zhenjiang and Yangzhou (1963), and Suzhou and Hangzhou (1965) (Shi Xiaofeng 2006, 332-35). 
health he enjoyed in this period brought him joy from travelling, as illustrated in a passage from a "New Year's" prose piece from February 1963 in which he summarizes the trips he had taken in recent years and at the same time mentions plans for future trips. ${ }^{43}$ The series of essays inspired by his journeys examined above, in which Feng Zikai strives to speak with his own voice, is complemented in an interesting manner by the 1962 essay “Everything Is New, Everything Is Arresting” (“Ermu yixin” 耳目一新). In the context of the era it was written in, it comes off as an extraordinarily open confession. Feng Zikai speaks about what travelling means to him. He does not, however, speak about destinations, places, or sights, but about travelling as a movement that offers the perceptive person many delights. He recalls the time when he left his home in Shimenwan only when he had to go to Hangzhou. Instead of taking the train, which would have brought him to the city in a matter of hours, he decided to travel by boat along a series of canals. The journey there and back lasted four days, and it provided him an opportunity for leisurely wandering, an important part of which was sleeping at moorages, visiting places along the banks, sampling local delicacies, and above all people-watching and making sketches. Feng Zikai ends his essay with the following words: "Back then many people mocked me for being foolish. But it brought me pleasure. To kill a little time, to spend a bit of money, but in return to see everything as if for the first time - it is worth it" (Feng Zikai wenji 6, 633). The essay's praise of "aimless", profoundly empathetic insight into phenomena and things gives us a glimpse of the "old" Feng Zikai who, not even when the nation's existence was under threat during the war, never abandoned his belief about the value of the delight that comes only from perceiving the world. ${ }^{44}$ In the new China, such an attitude was hardly permissible, but nonetheless Feng Zikai was unwilling to give it up.

The second half of the 1960s was clearly the most difficult period in Feng Zikai's life: the Cultural Revolution brought him four years of rejection, forced self-humiliation, and physical and psychological torment (Harbsmeier 1984, 40-41). Paradoxically, however, he did not have to insert parts of his authentic self into his essays, which upon initial reading often seem to offer stereotypical praise of the new China and its people. Feng Zikai lost the final remnant of his public voice, which he retained, as we have shown, during the late 1950s and early 1960s, but he did not let his inner voice be taken. He enjoyed secretly reading and copying old poetry (Barmé 2002,335) and especially writing memoir essays in which the authentic Feng Zikai, looking with enchanted eyes at his childhood and youth, speaks to us. ${ }^{45}$

43 See “Trying My Hand at Essaying during New Year's Time” (“Xinchun shibi” 新春试笔). Feng Zikai even happily announces that he is experiencing in his own body the renewal and rejuvenation of society (Feng Zikai wenji 6, 644).

44 This attitude is demonstrated in Feng Zikai's manhua from the 1940s, compelling depictions of people who in the midst of killing and destruction found delight in the details of daily life (Hawks 2017, 38).

45 Of the thirty-three personal essays that Feng Zikai secretly wrote in 1970-73, only seventeen of them, which had been altered or censored, were published, eight years after his death, no less (Feng Zikai wenji 6, 653). 


\section{BIBLIOGRAPHY}

An Dechang 安德昌 [Andrš, Dušan] (2005). “Ganqing yiru yu wuguanxin: Feng Zikai de zonghexing yishuguan jiedu” 感情移入与无关心：丰子恺的综合性艺术观解读. In: David Der-wei Wang and Kim Chew Ng (eds.), National Imaginaries: 15 Perspectives on Modern Chinese Literature. Taibei: Maitian chuban, 181-201.

Andrš, Dušan (2005). „Role umění v životě člověka: Feng Zikai a jeho př́íspěvek k čínské estetice první poloviny 20. století." Studia Orientalia Slovaca, vol. 4, 153-175.

Andrš, Dušan (2008). "Narrative Strategies in Modern Chinese Essay Writing: An Analysis of Essays by Feng Zikai and Lu Li." In: Olga Lomová (ed.), Paths Toward Modernity. Studia Orientalia Pragensia XXVI. Prague: Charles University, 395-418.

Barmé, Geremie R. (2002). An Artistic Exile: A Life of Feng Zikai (1898-1975). Berkeley: University of California Press.

Chen Xing 陈星 (2011). Feng Zikai pingzhuan 丰子恺评传 [A Critical Biography of Feng Zikai]. Jinan: Shandong huabao chubanshe.

Feng Yiyin 丰一吟 (1983). Feng Zikai zhuan丰子恺传 [A Biography of Feng Zikai]. Hangzhou: Zhejiang renmin chubanshe.

Feng Zikai wenji 丰子恺文集 [Collected Works of Feng Zikai] (1992). Vol. 3, 5, 6 Hangzhou: Zhejiang wenyi chubanshe, Zhejiang jiaoyu chubanshe.

Harbsmeier, Christoph (1984). The Cartoonist Feng Zikai: Social Realism with a Buddhist Face. Oslo: Universitetsforlaget.

Hawks, Shelley Drake (2017). The Art of Resistance: Painting by Candlelight in Mao's China. Seattle: University of Washington Press.

Shi Xiaofeng 石晓枫(2006). Baima hupande huiguang: Feng Zikai sanwen yanjiu 白马湖畔的辉光：丰子恺 散文研究. Taibei: Xiuwei zixun keji.

Spence, Jonathan D. (1990). The Search for Modern China. New York, London: W. W. Norton.

Zhuang, Sue (2020). "A Critical View of the Yangzhou Dream. Feng Zikai’s Essay “The Yangzhou Dream” (Yangzhou meng, 1958)." In: Roland Altenburger, Margaret B. Wan, Vibeke Børdahl (eds.), Yangzhou, A Place in Literature: The Local in Chinese Cultural History. Honolulu: University of Hawaii Press, 343-356. 